Article

\title{
Synergistic Effect of Pressurization Rate and $\beta$-Form Nucleating Agent on the Multi-Phase Crystallization of iPP
}

\author{
Wenxia Jia $^{1}$, Ranran Zhuo ${ }^{2}$, Mingkun Xu ${ }^{1}$, Jiaxiang Lin ${ }^{1}$, Xiaoting Li $^{1}$, Chuntai Liu ${ }^{1} \mathbb{D}$, Changyu Shen $^{1}$ \\ and Chunguang Shao ${ }^{1, * \mathbb{D}}$
}

1 Key Laboratory of Materials Processing and Mold, National Engineering Research Center for Advanced Polymer Processing Technology, Ministry of Education, Zhengzhou University, Zhengzhou 450002, China; zzdx2019628@163.com (W.J.); xumkofmail@163.com (M.X.); LJX950727@126.com (J.L.); zdlixt@163.com (X.L.); ctliu@zzu.edu.cn (C.L.); shency@zzu.edu.cn (C.S.)

2 School of Physics and Microelectronics, Zhengzhou University, Zhengzhou 450002, China; zhuoran242@zzu.edu.cn

* Correspondence: shaochg@zzu.edu.cn

check for updates

Citation: Jia, W.; Zhuo, R.; Xu, M.; Lin, J.; Li, X.; Liu, C.; Shen, C.; Shao, C. Synergistic Effect of Pressurization Rate and $\beta$-Form Nucleating Agent on the Multi-Phase Crystallization of iPP. Polymers 2021, 13, 2984. https:// doi.org/10.3390/polym13172984

Academic Editor: Jian-Yu Chen

Received: 22 July 2021

Accepted: 31 August 2021

Published: 3 September 2021

Publisher's Note: MDPI stays neutral with regard to jurisdictional claims in published maps and institutional affiliations.

Copyright: (c) 2021 by the authors. Licensee MDPI, Basel, Switzerland. This article is an open access article distributed under the terms and conditions of the Creative Commons Attribution (CC BY) license (https:// creativecommons.org/licenses/by/ $4.0 /)$.

\begin{abstract}
Using a homemade pressure device, we explored the synergistic effect of pressurization rate and $\beta$-form nucleating agent ( $\beta$-NA) on the crystallization of an isotactic polypropylene (iPP) melt. The obtained samples were characterized by combining small angle $X$-ray scattering and synchrotron wide angle $X$-ray diffraction. It was found that the synergistic application of pressurization and $\beta$-NA enables the preparation of a unique multi-phase crystallization of iPP, including $\beta-, \gamma$ - and/or mesomorphic phases. Pressurization rate plays a crucial role on the formation of different crystal phases. As the pressurization rate increases in a narrow range between $0.6-1.9 \mathrm{MPa} / \mathrm{s}$, a significant competitive formation between $\beta$ - and $\gamma$-iPP was detected, and their relative crystallinity are likely to be determined by the growth of the crystal. When the pressurization rate increases further, both $\beta$ - and $\gamma$-iPP contents gradually decrease, and the mesophase begins to emerge once it exceeds 15.0 MPa/s, then mesomorphic, $\beta$ - and $\gamma$ - iPP coexist with each other. Moreover, with different $\beta$-NA contents, the best pressurization rate for $\beta$-iPP growth is the same as $1.9 \mathrm{MPa} / \mathrm{s}$, while more $\beta-\mathrm{NA}$ just promotes the content of $\beta$-iPP under the rates lower than $1.9 \mathrm{MPa} / \mathrm{s}$. In addition to inducing the formation of $\beta$-iPP, it shows that $\beta$-NA can also significantly promote the formation of $\gamma$-iPP in a wide pressurization rate range between 3.8 to $75 \mathrm{MPa} / \mathrm{s}$. These results were elucidated by combining classical nucleation theory and the growth theory of different crystalline phases, and a theoretical model of the pressurization-induced crystallization is established, providing insight into understanding the multi-phase structure development of iPP.
\end{abstract}

Keywords: isotactic polypropylene; pressurization rate; $\beta$-form nucleating agent; multi-phase crystallization

\section{Introduction}

Isotactic polypropylene (iPP) possesses a specific position among semicrystalline polymers due to its comprehensive physical and chemical properties and good processing performance [1,2]. Its rich polymorphism, which has received substantial attention in scientific research and industrial applications, has a high effect on the properties [3,4]. iPP can form several crystal modifications including monoclinic $\alpha$-iPP, trigonal $\beta$-iPP, orthorhombic $\gamma$-iPP, and mesophase (intermediate state between ordered and amorphous phase), all sharing the same threefold conformation, but with different spatial arrangements of chains in the crystal lattice [5-11]. Though the most common crystalline phase of iPP is $\alpha$ phase when its melt solidifies under ordinary conditions, due to the presence of the lamellae interlocking effect, $\alpha$-iPP usually shows inferior ductility, which greatly limits its application. On the contrary, due to the absence of the special cross-hatching lamellar structure, $\beta$-iPP allows the initiation and propagation of plastic deformation more easily 
and then enhances the energy dissipation during deformation, so that it shows excellent toughness (including enhanced impact strength and improved elongation at break). Thus, the polymorphic crystallization of iPP has received substantial attention [12-15].

The addition of nucleating agents (NAs) is the most effective method to develop polymorphic crystallization of iPP [15-18]. Usually, NAs can decrease the nucleation activation energy during the crystallization process, leading to the crystallization occurring at relatively higher temperature (lower supercooling). Different kinds of NAs could promote the formation of the corresponding crystal phase according to the epitaxy theory, but this seems different in some circumstances, such as the crystallization under high pressure. Sowinski et al. have shown that under high pressure, iPP can be efficiently nucleated in the $\gamma$-form by poly(tetrafluoroethylene) and Hyperform HPN-20E, both of which are known to nucleate the strong crystallization of iPP in the $\alpha$-form at atmospheric pressure [19]. Zapala et al. demonstrated that under high pressure, the $\gamma$-iPP could be promoted by active heterogeneities, which were able to nucleate in $\alpha$-form [20]. In addition, we also found that multi-walled carbon nanotubes, a typical $\alpha$-NA, could promote the formation of $\gamma$-iPP under high pressure treatment, and successfully reinforce the products modulus and yield strength [21]. A reasonable explanation for these phenomena was pointed by Sowinski et al. [22], who said the high pressure facilitated the $\gamma / \alpha$ epitaxy growth in iPP, where the primary nucleation occurred in the $\alpha$-form on the surface of $\alpha$-NAs, followed by the growth of the $\gamma$ crystal. These results indicate that there was competition between the effect of $\alpha$-NAs, which promoted the formation of $\alpha$ phase, and the effect of high pressure that promoted the growth of $\gamma$-iPP.

It is well known that pressure could lead to an increase in equilibrium melting temperature of iPP and thus obtain the extra undercooling, which means that pressure may vary the nucleation density and the growth rate of different crystals [9,23-25]. Moreover, pressure is favorable for the growth of $\gamma$-iPP since the $\gamma$ phase has lower free energy than other crystal modifications at the elevated pressure $[26,27]$. Phillips and coworkers reported that the $\gamma$-iPP starts to form at a low pressure of about $50 \mathrm{MPa}$ and becomes dominant at a high pressure of about $200 \mathrm{MPa}$, accompanied by the decrease in $\alpha$-iPP [9]. Yang et al. have showed that pressure and flow can jointly induce "oriented" iPP spherulites consisting of $\alpha$ - and $\gamma$-modifications, while a high pressure was beneficial for $\gamma$-iPP formation, but flow brings an opposite effect [14]. Recently, we have observed the competitive formation of $\gamma$-iPP and mesophase under high-pressure treatment and presented the special dependence on the pressure and pressurization rate [28]. It has also been proven that the pressurization method can get rid of thermal conductivity of the melt and would produce products with a more uniform structure with a larger size, which seems effective to optimize the mechanical properties of polymer products $[29,30]$.

When NAs and pressure treatment take effect simultaneously, an effective approach may be developed to improve iPP polymorphic crystallization [12,19,31]. However, as mentioned above, till now most of the research focuses on iPP mixed with $\alpha$-NAs, but few reports have devoted to the effects of pressure on crystallization of iPP containing $\beta$-NAs. Obadal et al. proposed that aryl amide derivative (a kind of $\beta$-NA) enhanced the formation of the $\gamma$-iPP during isothermal crystallization at a lower pressure or at a high pressure but low temperature [31]. Yang et al. reported an increase in $\gamma$-iPP and a decrease in $\beta$-iPP with increasing pressure in iPP nucleated with aryl amide derivative, and they found $\gamma$-iPP could grow on the lateral of the $\beta$-NA needlelike structure and attributed it to the dual nucleation effects of $\beta$-NA [32]. However, Sowinski et al. reported that calcium pimelate, another typical kind of $\beta$-NA, only has a slight effect on the crystallization of $\gamma$-iPP under a high pressure [33]. Despite these contributions, the debates are still apparent, and the crucial question is whether $\beta$-NA can promote the formation of $\gamma$-iPP and whether there exists a competition between $\beta$ - and $\gamma$-iPP under high pressure treatment [19]. To our knowledge, the crystallization behavior of iPP under the synergistic effect of $\beta$-NA and pressurization treatment has not been investigated before. 
In the current work, we studied the crystalline structure of iPP mixed with $\beta$-NA (rare earth nucleator) crystallized under a widely-ranging pressurization rate from $0.6-750 \mathrm{MPa} / \mathrm{s}$. For the first time, we observed the competitive formation of $\beta-, \gamma$ - and mesomorphic iPP during the pressurization treatment, and displayed their relative content changes as a function of pressurization rate. Moreover, we revealed the versatile role of $\beta$-NA in the formation of $\beta$ - and $\gamma$-iPP by combining nucleation and growth theory of different crystalline phases. Furthermore, a theoretical model was given to illustrate the solidification of iPP melts under pressurization treatment, providing insights into understanding the multiphase structure development of iPP induced by the synergistic effect of pressurization rate and $\beta$-NA.

\section{Materials and Methods}

\subsection{Materials}

The iPP material (grade T30s) used in this study has a weight average molecular weight $\mathrm{Mw}=399 \mathrm{~kg} / \mathrm{mol}$ and a polydispersity $\mathrm{Mw} / \mathrm{Mn}=4.6$, which was kindly supplied by Dushanzi Petroleum Chemical Co, Korla, China. The rare earth nucleator (WBG-II), a typical kind of $\beta$-NA, was supplied by Guangdong Winner Functional Materials Co., Ltd. (Guangdong, China). $\beta$-NA is a heteronuclear dimetal complex of lanthanum and calcium with some specific ligands. Its general formula is $\mathrm{Ca}_{\mathrm{x}} \mathrm{La}_{1-\mathrm{x}}(\mathrm{LIG1})_{\mathrm{m}}(\mathrm{LIG} 2)_{\mathrm{n}}$, where $\mathrm{x}$ and $1-x$ are the proportions of $\mathrm{Ca}^{2+}$ and $\mathrm{La}^{3+}$ ions in the complex, while LIG1 and LIG2 are, respectively, a dicarboxylic acid and amidetype ligand with a coordination number of $\mathrm{m}$ and $\mathrm{n}$.

\subsection{Preparation of Samples}

The iPP granules and $\beta$-NA were firstly dried in a vacuum oven at $80{ }^{\circ} \mathrm{C}$ for $8 \mathrm{~h}$. To achieve a good dispersion of $\beta$-NA in iPP a two-step process was employed. Namely, a master batch of $5 \mathrm{wt} \% \beta$-NA in iPP was first prepared through melt blending of $\beta$-NA and iPP in a Haake MiniLab II twin-screw extruder for $7 \mathrm{~min}$ at $30 \mathrm{rpm}$ and $200{ }^{\circ} \mathrm{C}$, and then the master batch was diluted with iPP to obtain the desired iPP/WBG-II composition (iPP with 0.2 and $0.5 \mathrm{wt} \% \beta-\mathrm{NA}$, marked as iPP0.2 and iPP0.5). After being pelletized, the composites were compression-molded into circular samples with a diameter of $24 \mathrm{~mm}$ and a thickness of $1 \mathrm{~mm}$. For comparison, the circular samples without $\beta$-NA blending (marked as iPP0) were also prepared.

The high-pressure treatment was performed on a homemade pressure device, and the sample assembly is shown in Figure 1a, whose detailed information has been described in previous work $[28,34]$. The experimental pressure and temperature profiles are shown in Figure $1 \mathrm{~b}$. The specimen was placed between two aluminum plates and pressed by two opposing pistons under a desired pressure within a certain time, and the required temperature was supplied by the outer heating jacket. The experimental procedure was as follows: after loading the specimen, a relatively low pressure (10 MPa) was applied, and the sample was heated to $20{ }^{\circ} \mathrm{C}$ and annealed at this temperature for $10 \mathrm{~min}$ to erase processing histories; in order to ensure that the sample has solidified at the end of pressurization, the desired pressure was set at 1.7 GPa so as to obtain a sufficiently high undercooling [28,34], then the relaxed melt at $200^{\circ} \mathrm{C}$ were pressurized to $1.7 \mathrm{GPa}$ within the controllable durations of $2,22,34,45,113,226,453,895,1308,2125$, and $2833 \mathrm{~s}$, respectively, which correspond to the wide pressurization rate ranging from $0.6-750 \mathrm{MPa} / \mathrm{s}$; subsequently, the pressurized samples were immediately cooled down to $40{ }^{\circ} \mathrm{C}$ at an average cooling rate of about $10^{\circ} \mathrm{C} / \mathrm{min}$ under $1.7 \mathrm{GPa}$; at last, the pressure was completely released to obtain the solidified samples. For comparison, another group of samples were prepared by heated to $200{ }^{\circ} \mathrm{C}$, annealed for $10 \mathrm{~min}$, and then cooled down to $40{ }^{\circ} \mathrm{C}$ under atmospheric pressure. 


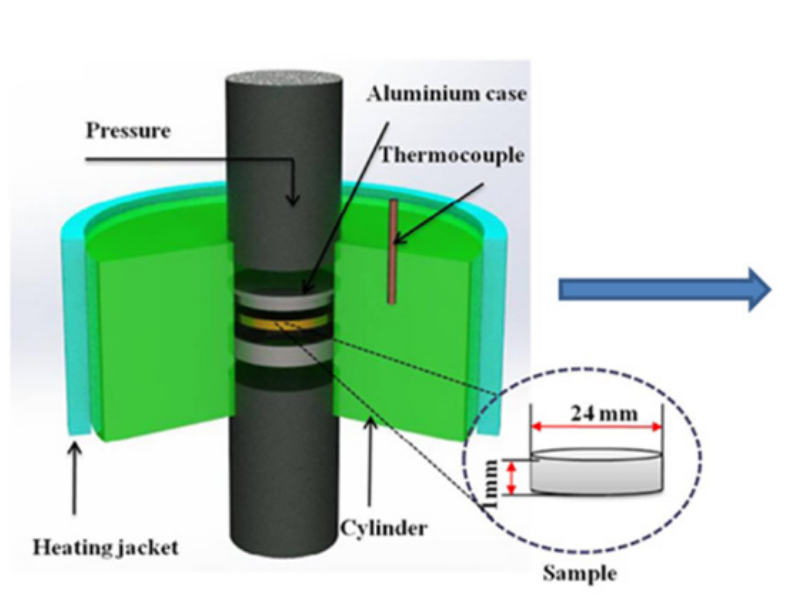

(a)

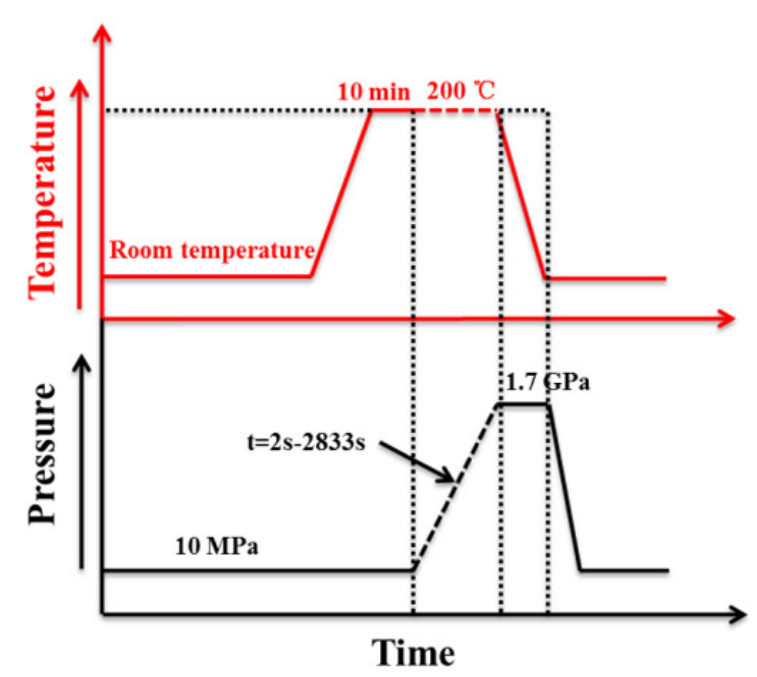

(b)

Figure 1. (a) Schematic of the high-pressure cell; (b) the temperature and pressure protocol.

\subsection{Characterizations}

\subsubsection{Synchrotron Wide-Angle X-ray Diffraction}

Synchrotron wide-angle X-ray diffraction (SR WAXD) measurements were carried out at the beamline BL16B of the Shanghai Synchrotron Radiation Facility (SSRF) with a wavelength $(\lambda)$ of $0.124 \mathrm{~nm}$. A Pilatus $200 \mathrm{~K}$ detector $(487 \times 407$ pixels with a pixel size of $172 \mu \mathrm{m}$ ) was employed to collect the two-dimensional (2D) scattering patterns. The sample to detector distance was $227.3 \mathrm{~mm}$. The exposure time was $10 \mathrm{~s}$ for each pattern. Fit2D software was used to analyze the data quantitatively. The 2D WAXD patterns were integrated to obtain the scattering intensity as a function of $2 \theta$ after correcting for background scattering from the air and sample holder.

The one-dimensional (1D) WAXD curves were fitted according to Gaussian functions to obtain the crystallinities of the samples. The phase content can be estimated by the following equation based on an interactive peak fit procedure [34]:

$$
X_{i}=A_{i} /\left(A_{\gamma}+A_{\beta}+A_{\text {meso }}+A_{\text {amorp }}\right)
$$

where $i$ represents the specific crystal phase (either $\gamma, \beta$, mesophase or amorphous) and $A_{i}$ represents the area of the fitted Lorentzian curve of the specific reflection. $A_{\text {meso }}, A_{\gamma}, A_{\beta}$, and $A_{\text {amorp }}$ are the fitted areas of mesomorphic, $\gamma-, \beta$ - and amorphous phases, respectively. The crystalline size $\left(D_{h k l}\right)$ determined in the direction perpendicular to (hkl) plane was estimated by using the Debye-Scherrer's equation [3]:

$$
D_{h k l}=k \lambda / \beta_{h k l} \cos \theta_{h k l}
$$

where $\lambda$ is the wavelength of the $\mathrm{X}$-ray, $k$ is crystallite shape factor (0.89), $\theta_{h k l}$ is the Bragg angle, and $\beta_{h k l}$ is the full width at half maximum (FWHM) of the diffraction peak.

\subsubsection{Small-Angle $X$-ray Scattering}

Small-angle X-ray scattering (SAXS) measurements were conducted using a Bruker Nanostar system. The operating voltage and current are $45 \mathrm{kV}$ and $0.65 \mathrm{~mA}$, respectively. SAXS patterns were recorded by a 2D vant 2000 detector. The wavelength of the X-ray used was $0.154 \mathrm{~nm}$ and the sample to detector distance was $1085 \mathrm{~mm}$. The exposure time was $600 \mathrm{~s}$ for each scattering pattern. 
Fit2D software was used to integrate the 2D SAXS results to $1 \mathrm{D}$ intensity distribution as a function of the module of scattering vector $q=4 \pi \sin \theta / \lambda$ with $2 \theta$ being the scatter angle and $\lambda$ the $X$-ray wavelength. Through the 1D integrated curves, the peak position $\left(q_{\max }\right)$ can be obtained. According to the Bragg's equation, the long period (L) of lamellae is calculated as follows:

$$
\mathrm{L}=2 \pi / q_{\max }
$$

\section{Results}

\subsection{Crystallization of iPP and iPP/WBG-II under Atmospheric Pressure}

Before high-pressure treatment, the crystalline structure and melting behavior of iPP0, iPP0.2, and iPP0.5 samples prepared by cooling under atmospheric pressure were characterized by SR WAXD, as shown in Figure 2. For iPP0 samples, the characteristic diffraction peaks of (110), (040), (130), (111), and (131) crystal planes of $\alpha$-iPP were identified. On the other hand, iPP/WBG-II samples exhibit the typical characteristic diffraction peaks at $2 \theta=12.9^{\circ}$ and $17.0^{\circ}$, corresponding to (110) and (301) planes of $\beta$-iPP, and one weak diffraction peak of the $\alpha$-iPP (110) plane can also be observed in iPP/WBG-II WAXD curves, which means a little amount of $\alpha$-iPP was formed. This means that although WBG-II is an effective $\beta$-NA for iPP [35], it does not prevent the nucleation and growth of $\alpha$-crystal. Moreover, there is no obvious difference between iPP0.2 and iPP0.5 WAXD curves, and the $\mathrm{X}_{\beta}$ of iPP0.2 and iPP0.5 are calculated to be 0.89 and 0.90 , respectively.

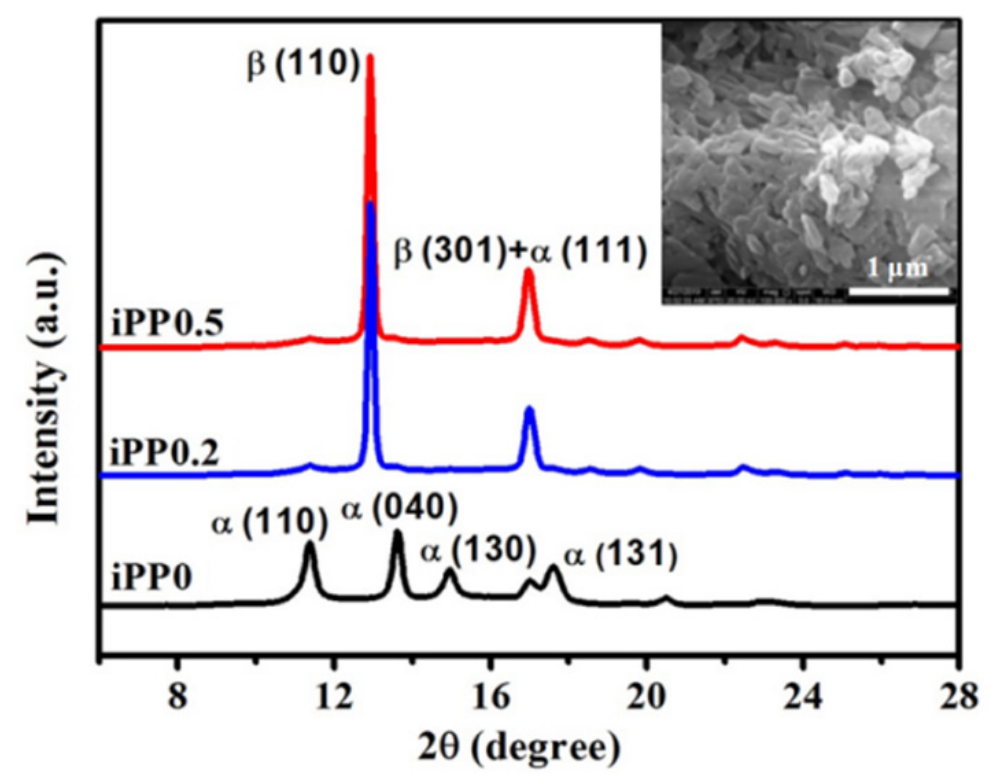

Figure 2. 1D WAXD profiles of iPP0, iPP0.2, and iPP0.5 samples crystallized under atmospheric pressure (the inset shows scanning electronic microscopy micrograph of WBG-II, supplied by the provider).

\subsection{Effect of Pressurization Rate on Polymorphic Crystallization of iPP0.2}

SR WAXD was used to detect the polymorphic composition of the high-pressure treated iPP0.2 samples. Figure 3a shows their 2D WAXD patterns, which shows that no orientation of the crystalline or amorphous phase was detected for all the samples, meaning the mold utilized in this experiment was well sealed and no flow occurred during the pressurization process [21]. Their 1D WAXD curves under different pressurization rates was given in Figure 3b, where no reflections corresponding to $\alpha$-iPP were observed. At the lowest pressurization rate of $0.6 \mathrm{MPa} / \mathrm{s}$, the characteristic diffraction peaks at $2 \theta=11.3^{\circ}(111), 13.5^{\circ}(008), 16.0^{\circ}(117)$, and $16.8^{\circ}$ (202) attributed to $\gamma$-iPP can be observed, while the typical characteristic diffractions at $2 \theta=12.9^{\circ}$ for the $\beta$-iPP (110) plane was also identified. With the increasing of the pressurization rate, the intensity of (111), (008), 
(117), and (202) peaks decrease observably, demonstrating the content of the $\gamma$-iPP decrease remarkably. Differently, the intensity of $\beta$-iPP (110) increases at the initial pressurization rate increase and achieves the maximum as it reaches $1.9 \mathrm{MPa} / \mathrm{s}$, then gradually reduces. Moreover, when the pressurization rate adds up higher than $75 \mathrm{MPa} / \mathrm{s}$, all these crystal diffractions disappear and pure mesophase with two broad scattering halos at $2 \theta$ of $11.9^{\circ}$ and $17.0^{\circ}$ appear.

(a)

(c)
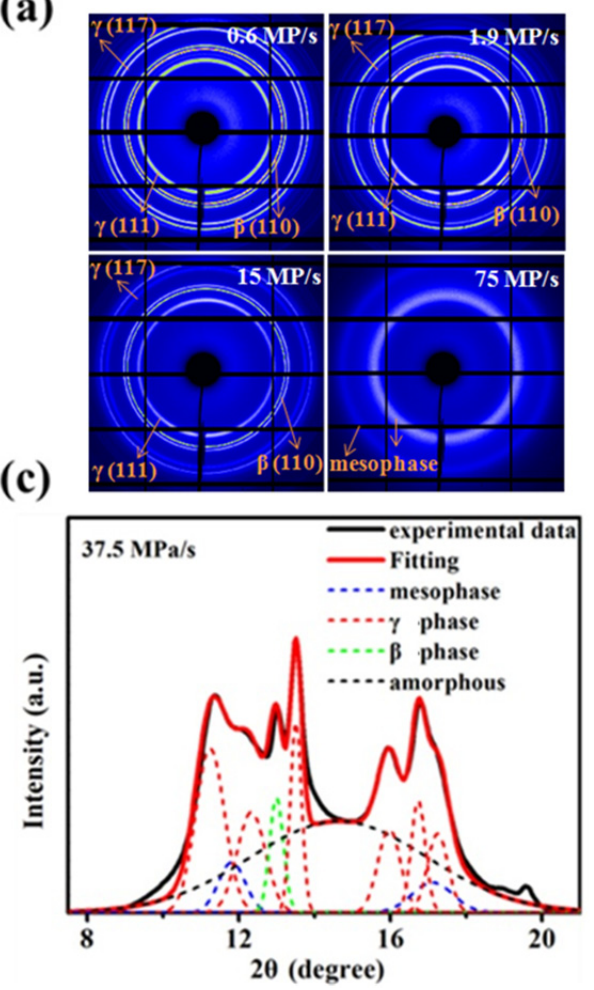

(b)

(d)
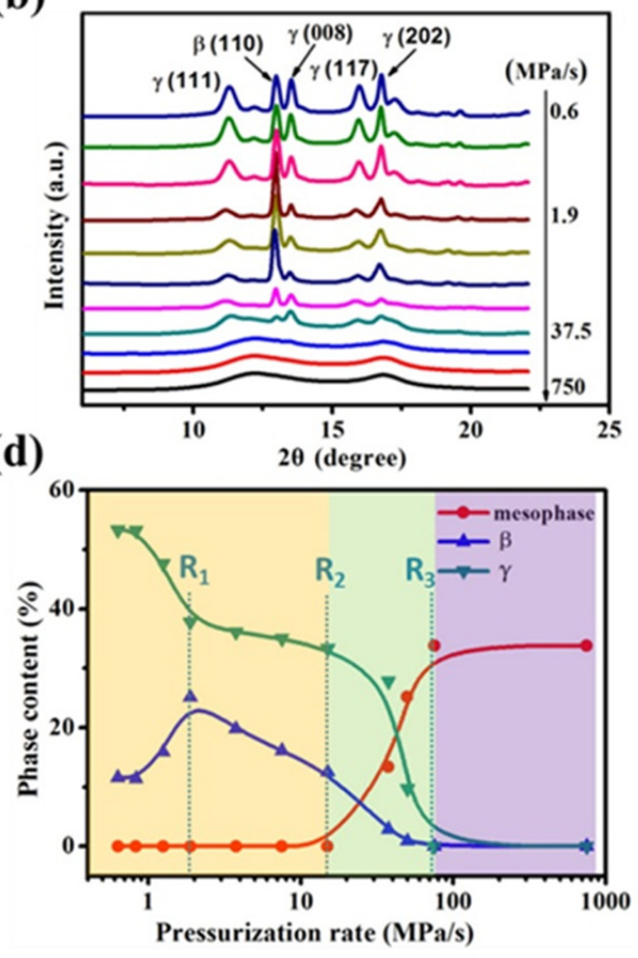

Figure 3. (a) Selected 2D WAXD patterns and (b) 1D WAXD profiles of iPP0.2 samples solidified by pressuring to $1.7 \mathrm{GPa}$ at different pressurization rates; (c) the fitting curves of WAXD of amorphous, mesomorphic, $\beta$ - and $\gamma$-phases; (d) fractions of different phases as a function of pressurization rates.

To quantify the changes in crystallization polymorphism, the 1D WAXD signals were decomposed into specific contributions from $\gamma-, \beta-$, mesomorphic, and amorphous phases, see the representative fitting in Figure $3 c$ [36], which displays a representative fitting performed on the WAXD profiles. Figure $3 \mathrm{~d}$ presents the changes of the phase contents as a function of pressurization rate, and three critical rates (indicated by dotted lines) were identified. For simplified analysis, the amorphous phase is not taken into consideration. It can be seen that, at the lowest pressurization rate of $0.6 \mathrm{MPa} / \mathrm{s}$, only $\beta$ - and $\gamma$-iPP were obtained with the fractions of $11 \%$ and $54 \%$, respectively. When the pressurization rate increases to $1.9 \mathrm{MPa} / \mathrm{s}$ (denoted as $\mathbf{R}_{\mathbf{1}}$ ), it causes an obvious decrease in $\gamma$-iPP crystallinity from $54 \%$ to $40 \%$, but the crystallinity of $\beta$-iPP increases visibly from $11 \%$ to the maximum point of about $24 \%$. The increase in $\beta$-iPP crystallinity is almost equal to the decrease in $\gamma$-iPP crystallinity, meaning that the content of $\beta$-iPP increases at cost of the $\gamma$-iPP $[25,37]$. Once that rate exceeds $\mathbf{R}_{\mathbf{1}}, \beta$-iPP and $\gamma$-iPP crystallinities both decrease gradually. When that rate further exceeds $15 \mathrm{MPa} / \mathrm{s}$ (denoted as $\mathbf{R}_{\mathbf{2}}$ ), the mesophase begins to emerge, and mesomorphic, $\beta$-, and $\gamma$-iPP coexist with each other. After reaching $75 \mathrm{MPa} / \mathrm{s}$ (denoted as $\mathbf{R}_{3}$ ), pure mesophase could be obtained and its fraction content reaches the maximum of about $32 \%$. It is worth noting that with pressurization, the formation of metastable structures has been observed for different kinds of polymers, and for iPP pressurization can induce more effects than temperature cooling on the formation of mesophase [38,39]. 
Crystal perfection was studied to understand the formation of the $\beta$ - and $\gamma$-phase induced by pressurization. Figure 4 displays the corresponding crystallite size $\mathrm{D}$ calculated by using the Debye-Scherrer's equation. Clearly, within the range of 0.6 to $1.9 \mathrm{MPa} / \mathrm{s}$ $\left(\mathbf{R}_{1}\right), \mathrm{D}(008)$ of the $\gamma$ crystal decreases rapidly from about 29.2 to $22.0 \mathrm{~nm}$, and D (117) decreases from about 14.0 to $11.5 \mathrm{~nm}$, indicating that the pressurization rate increasing greatly suppresses the growth of $\gamma$ crystal. Instead, D (110) of the $\beta$ crystal increases clearly from about 21.6 to $25.6 \mathrm{~nm}$. With that rate enhanced greater than $\mathbf{R}_{1}$, both the $\gamma$ and $\beta$ crystals were restrained and their size reduces gradually. Interestingly, it can be found that, for the $\beta$ crystal or $\gamma$ crystal, the changing trend of its crystallite size is similar to that of its crystallinity (in Figure 3d); thus, we deduced that the crystallite size change is probable to induce the phase content change as well as the competitive formation between the $\beta$ and $\gamma$ phase.

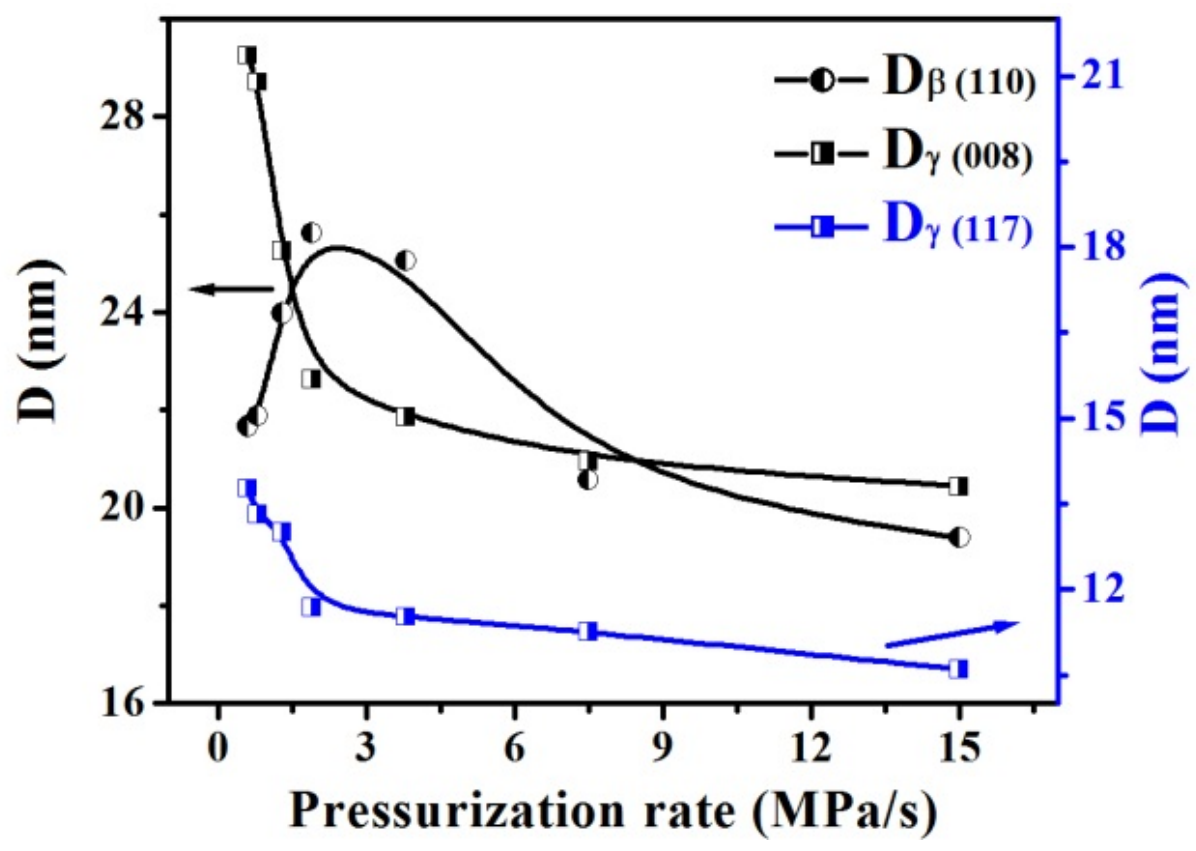

Figure 4. Changes in the crystallite size D for $\beta$ and $\gamma$ crystal as a function of pressurization rates.

SAXS was used to obtain the lamellae information. Figure 5a shows the Lorentzcorrected intensity plots as a function of scattering vector $(q=4 \pi \sin \theta / \lambda)$. For the iPP0.2 sample treated at a rate of $0.6 \mathrm{MPa} / \mathrm{s}$, two scattering peaks named $q_{1}$ and $q_{2}$ of 0.32 and $0.59 \mathrm{~nm}^{-1}$ were observed, which are close to that of pure $\beta$ and $\gamma$ crystal of iPP, respectively (Figure $5 b$ ). Figure $5 c$ summarized the change trend of the maximum intensity $\left(I_{\max }\right)$ of the scattering peaks. With the increasing pressurization rate, the $I_{\max }$ of the first peak adds in the early stage until it reaches $\mathbf{R}_{\mathbf{1}}$, and then decreases observably, consistent with the change trend of $\beta$-iPP crystallinity (Figure 3d). Similarly, the $I_{\max }$ of the second peak decreases with the pressurization rate increase, analogous to the change trend of $\gamma$-iPP content. Thereby, we attribute the first and second scattering peak to $\beta$ - and $\gamma$-iPP lamellae stacks, respectively. Figure $5 \mathrm{c}$ also shows the evolution of relative long period $\mathrm{L}$ that is determined by using the Bragg law. The crystallized samples seem to have two divided long-period peaks, demonstrating that the crystals of $\beta$ - and $\gamma$-iPP are present in the respective lamellae within different spherulites. It displays that when the pressurization rate increases from $0.6 \mathrm{MPa} / \mathrm{s}$ to $\mathbf{R}_{\mathbf{1}}$, L of $\beta$ crystal decreases slightly from about 19.0 to $18.0 \mathrm{~nm}$, while the $\mathrm{L}$ of the $\gamma$ crystal decreases remarkably from about 13.0 to $10.5 \mathrm{~nm}$. The decrease in L corresponds to the decrease in lamellae thickness, meaning the small increase in the pressurization rate can suppress the growth of lamellae, and this inhibition effect in $\gamma$ crystal seems more pronounced than that in $\beta$ crystal. This behavior is consistent with the thermodynamic 
arguments made by Keller et al. and Troisi et al., which explained the lamellar thinning mechanism as being due to the pressure raised during crystallization [40,41]. We inferred that the crystallization would take place at a higher pressure under a higher pressurization rate, which would induce a higher supercooling degree for crystallization, thereby result in thinner lamellar thickness as well as the smaller crystallite size, as shown in Figure 4.

(a)
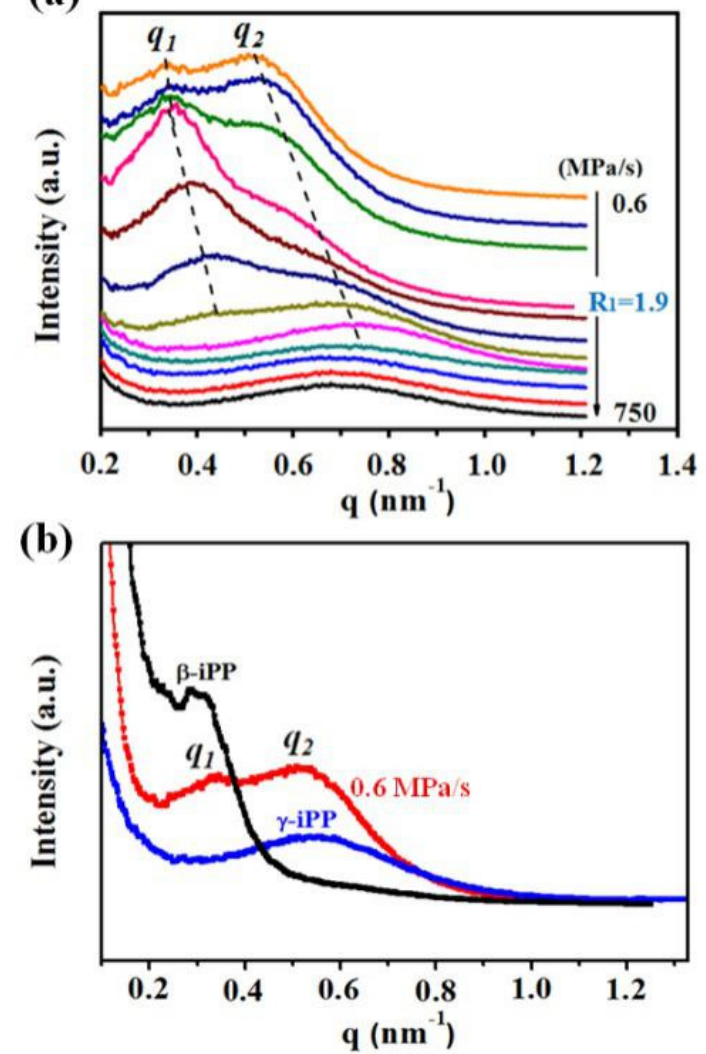

\section{(c)}

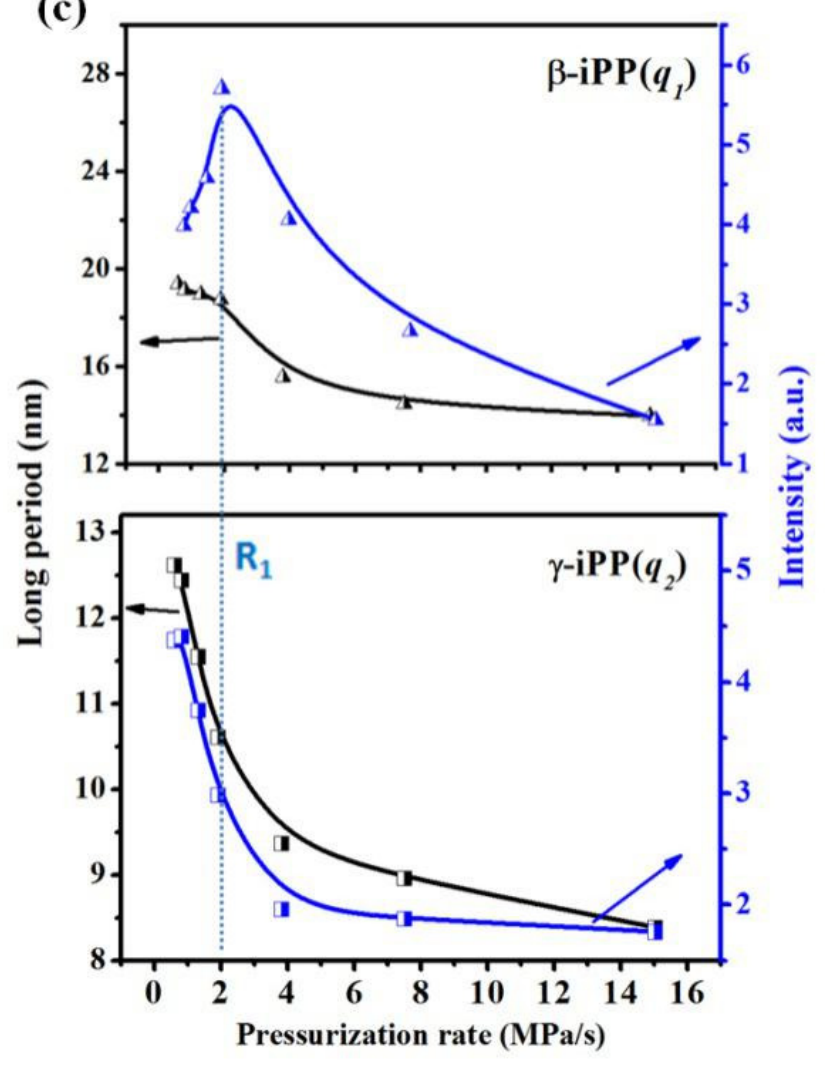

Figure 5. (a) Selected SAXS profiles of the iPP0.2 samples solidified by pressuring to $1.7 \mathrm{GPa}$ at different pressurization rates; (b) Comparison of the SAXS profiles between pure $\beta-, \gamma$-iPP and the iPP0.2 samples prepared by pressuring at $0.6 \mathrm{MPa} / \mathrm{s}$;

(c) Changes in the maximal intensity of $\gamma$ - and $\beta$-iPP as a function of pressurization rates.

\subsection{Synergistic Effect of Pressurization Rate and $\beta-N A$ on Polymorphic Crystallization of iPP}

In order to clarify the effect of $\beta-\mathrm{NA}$ on iPP crystallization behavior, the crystallization evolution of iPP0 and iPP0.5 melts under different pressurization rates were also studied, and their results were, respectively, compared with that of iPP0.2. Figure 6 displays the comparison of crystallization evolution in iPP0 and iPP0.2. For neat iPP, no $\beta$-iPP was induced by pressurization, and two threshold pressurization rates can be identified, of which the first one is about $1.9 \mathrm{MPa} / \mathrm{s}$ where mesophase starts to appear and the second one is about $15.0 \mathrm{MPa} / \mathrm{s}$ where only mesophase forms, see Figure 6a. In addition, the maximum $\gamma$-iPP crystallinity of about $63 \%$ can be obtained at the lowest pressurization rate of $0.6 \mathrm{MPa} / \mathrm{s}$, indicating low pressurization rate was benefit for $\gamma$-iPP formation and a small increase in that rate can restrain that formation, leading to a significant reduction of its crystallinity. It should be noted that the corresponding threshold pressurization rates of the iPP0.2 $\left(\mathbf{R}_{\mathbf{2}}=15 \mathrm{MPa} / \mathrm{s}, \mathbf{R}_{\mathbf{3}}=75 \mathrm{MPa} / \mathrm{s}\right)$ are much higher than that for neat iPP (1.9 MPa/s and $15 \mathrm{MPa} / \mathrm{s}$, respectively) as shown in Figure $6 \mathrm{~b}$, and the shifts of the threshold values indicate that $\beta$-NA can promote the formation of $\gamma$-iPP crystal and thus suppress mesophase formation, especially in the pressurization rate range from 3.8 to $75 \mathrm{MPa} / \mathrm{s}$. 

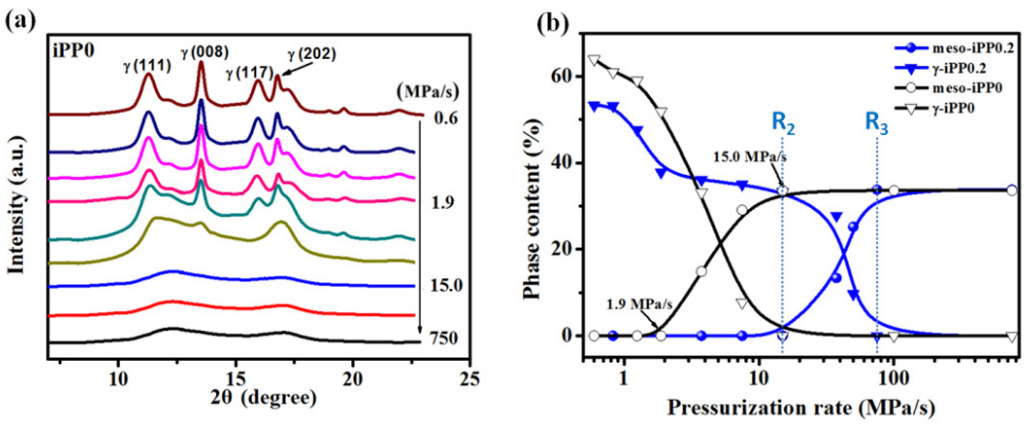

Figure 6. (a) Selected 1D WAXD profiles of iPP0 samples solidified by pressuring to $1.7 \mathrm{GPa}$ at different pressurization rates; (b) Contents of $\beta$ phase and $\gamma$ phase as a function of pressurization rate.

Figure 7 presents relative comparisons of iPP0.2 and iPP0.5 samples. Figure 7a shows that the change of different phase contents of iPP0.5 has a similar tendency as that of iPP0.2 with the pressurization rate changing, and three critical rates can also be identified. Further, the content of the $\beta$ phase in iPP0.5 is obviously higher at the rate lower than $\mathbf{R}_{\mathbf{1}}$, about $7 \%$ higher at $0.6 \mathrm{MPa} / \mathrm{s}$ for instance. However, the difference between their $\beta$-iPP contents gets smaller and even invisible after the rate reaches $\mathbf{R}_{\mathbf{2}}$. These results indicated that more $\beta$-NA can provide more nucleated sites and promote the formation of $\beta$-iPP under the pressurization rate lower than $\mathbf{R}_{1}$, beyond which this promotion effect gradually diminishes. Additionally, the difference in the mesophase content is slight between iPP0.2 and iPP0.5, meaning $\beta$-NA content rarely has an effect on the formation of mesophase, see Figure $7 \mathrm{~b}$. Furthermore, the D (110) of iPP0.5 $\beta$ crystals were also calculated as shown in Figure $7 \mathrm{c}$, from which it can be seen that $\mathbf{R}_{\mathbf{1}}$ is also the dividing line, and its value coincides very well with that of iPP0.2. The long period and scattering intensity of iPP0.5 $\beta$ crystals were displayed in Figure $7 d$, in which $I_{\max }$ firstly increases and latterly decreases while $\mathrm{L}$ decreases monotonically, but slight differences were found with that of iPP0.2. As a result, a conclusion can be drawn that the growth of $\beta$-iPP crystal is solely controlled by the pressurization rate but is hardly influenced by $\beta$-NA content in the range used in this study.
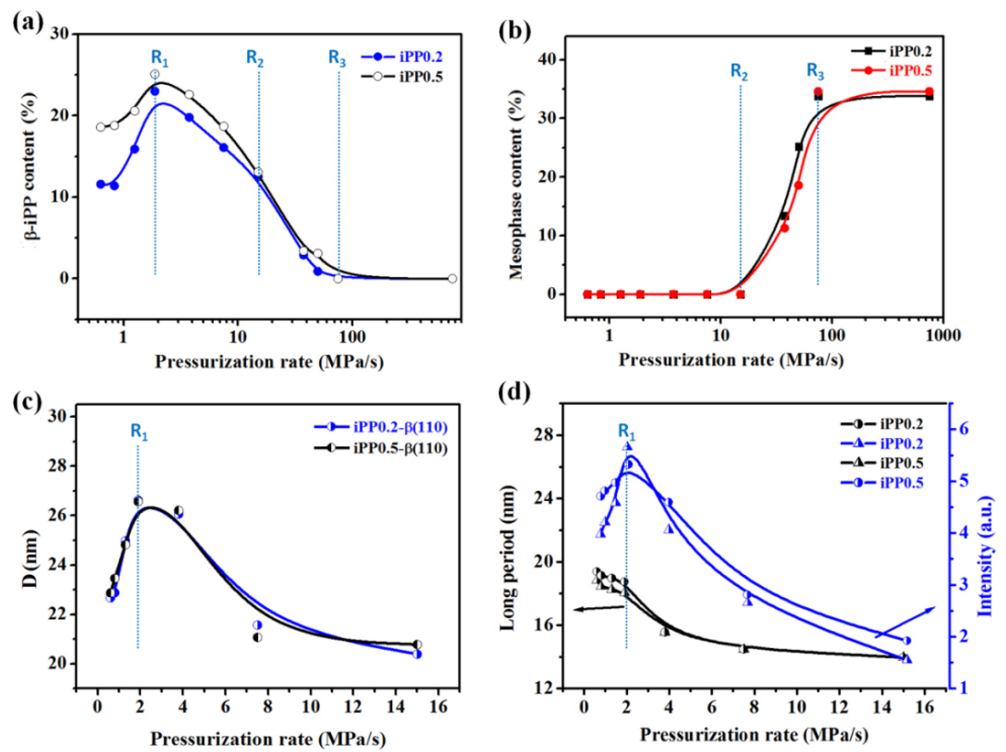

Figure 7. (a) Contents of $\beta$ - and (b) mesomorphic phases of iPP0.2 and iPP0.5 as a function of pressurization rate; (c) Changes in D and (d) L, $I_{\max }$ of $\beta$ crystal in iPP0.2 and iPP0.5 samples with pressurization rates. 


\section{Discussion}

It is known that the thermodynamic effect of pressure elevation is an undercooling increase of a given crystalline form, which is the driving force for crystallization. Herein, for the polymers whose melting points increase with pressure, solidification condition of melts can be changed by adjusting pressurization rate, namely non-isobaric crystallization [42,43]. For iPP, the equilibrium melting temperature $\left(T_{m}^{0}(P)\right)$ enhanced with the pressure increase, while the relation between iPP $\left(T_{m}^{0}(P)\right)$ and pressure $(P)$ usually can be expressed as follows [9]:

$$
T_{m}^{0}(P)=T_{m}^{0}+\zeta\left(P-P_{0}\right)
$$

where $P_{0}$ is the atmospheric pressure, $T_{m}^{0}$ is the equilibrium melting temperature at $P_{0} . \zeta$ is the pressure dependence of the melting temperature and could be applied as $0.3{ }^{\circ} \mathrm{C} / \mathrm{MPa}$ at low pressure, while in this case, $T_{m}^{0}(P)$ changes linearly with pressure. However, at a high pressure, $\zeta$ is not a constant but decreases with increasing pressure. Considering the experimental results of the literature, and in order to simplify the problem, we assume that $\beta$ and $\gamma$ phases share the same temperature and pressure dependence [25]. Therefore, the crystallization behavior of iPP melts under pressurization treatment can be correlated with the same equilibrium melting temperatures, and accordingly, the solidification of iPP melts could be divided into four regions labeled I, II, III, and IV, respectively, as shown in Figure 8.

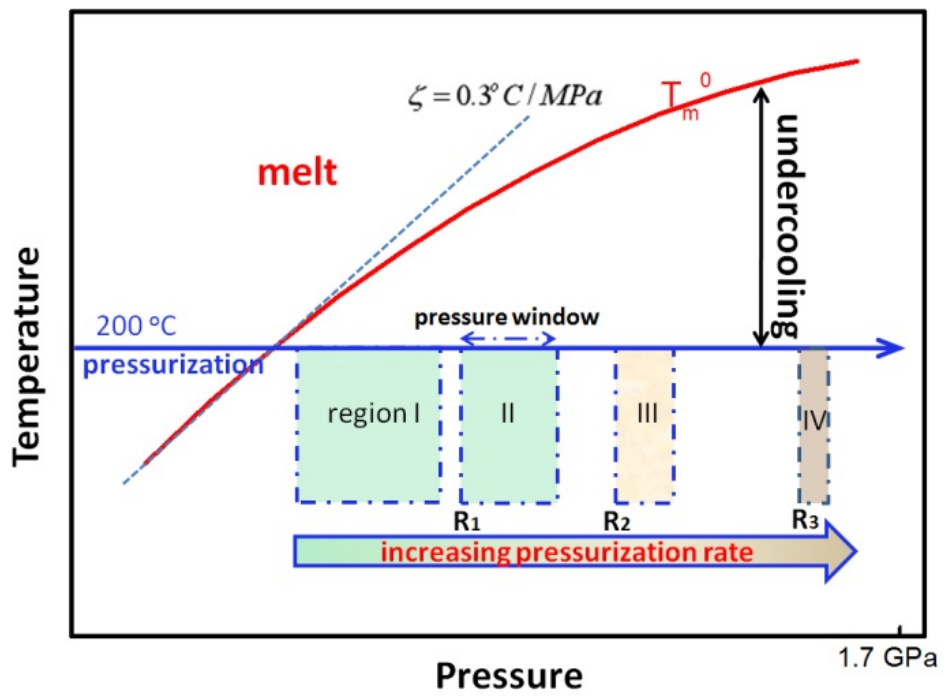

Figure 8. Theoretical model of the pressurization induced crystallization of $\beta$-NA blended iPP in the pressure-temperature diagram.

A certain crystal fraction will only increase noticeably if the nuclei are appointed to this crystal phase and the growth rate of that phase is significant [25,44]. In region I, the pressurization rate is low, solidification of iPP melt will start at a low pressure. From the thermodynamics perspective, a low pressurization rate provides low undercooling, and the pressure window for the crystallization to take place is wide $[10,14]$. Therefore, the iPP melt tends to form $\gamma$-iPP which has better thermal stability and lower free energy than that of $\beta$-iPP, and the $\gamma$ crystal will generate and grow into spherulites consisting of $\gamma$ lamellae. Hence, the lowest pressurization rate corresponds to the maximum crystallinity of $\gamma$-iPP, agreeing well with Mezghani and Phillips' report [45]. Meanwhile, from the kinetic perspective, the molecular chains have an enhanced ability of motion because of the low undercooling, hereafter benefitting from the growth of the $\gamma$ crystal; thus, perfected $\gamma$ crystals with thick lamellae will be obtained. However, the secondary nucleation can be simultaneously introduced by the addition of $\beta$-NA, which could provide a large quantity 
of nucleation sites for $\beta$ crystal growth [18]. Hence, the competitive formation between $\beta$ and $\gamma$ crystal is present (Figure 3d).

In region II, the melts are treated by a higher pressurization rate, so that solidification should start at a higher pressure; then, a higher undercooling will be introduced, and the pressure window in which the crystallization occurs usually decreases. Two possible explanations are introduced to interpret the competitive crystallization behavior between $\beta$ and $\gamma$ crystals in this region. First, when the pressurization rate rises, it can significantly restrain and shorten the growth time of the $\gamma$ crystal and lead to the sharp decrease in $\gamma$ crystal size, which provides more space for $\beta$ crystal growth. Second, it has been proven that there is an optimal undercooling for $\beta$ crystal growth at atmosphere pressure in the temperature range of $100-135{ }^{\circ} \mathrm{C}$ where the $\beta$ crystal can grow faster [44,46,47], while Van Erp and Peters et al. suggested that under high pressure a constant undercooling range of $60-90{ }^{\circ} \mathrm{C}$ is benefit for the growth of $\beta$ crystal [48]. On this basis, we consider that the undercooling induced by the pressurization rate of $\mathbf{R}_{\mathbf{1}}$ is likely to be in the range of $60-90{ }^{\circ} \mathrm{C}$ favorable to $\beta$ crystal growth [31]. In addition, as displayed in Figure 7c, the optical pressurization rate of $\mathbf{R}_{\mathbf{1}}$ for $\beta$ crystal growth was not influenced by $\beta$-NA contents, which can further prove the correctness of this conjecture.

When a high pressurization rate $\left(>\mathbf{R}_{2}\right)$ is used, a sufficient high undercooling and solidifying rate will be provided, and region III will be reached, where macromolecular chains in the melt has limited time to pack their segmental stems orderly. The nucleation behavior of the melt would change gradually from heterogeneous nucleation at a low supercooling to homogeneous nucleation at high supercooling [39,49,50], then metastable phase (or even amorphous) begins to be sought out and obeys the "law of successive states" [51,52]. However, with the existence of $\beta$-NA, the situation will be different from that of neat samples. NAs can induce the crystallization to take place at a lower pressure, namely at the lower supercooling, which is beneficial for the formation of $\gamma$-iPP. In this way, $\beta$-NA tends to suppress the generation of mesophase, and significantly promotes the formation of $\gamma$-iPP.

When the pressure increase is sufficiently high and rapid, as the pressurization rate rises greater than $\mathbf{R}_{3}$, region IV will be reached, where the pure mesophase can be obtained. Actually, for polymers whose melting point increases with increasing pressure, if the increase in pressure is high and rapid enough, the melt would be solidified to the metastable or even amorphous phase because of the sufficient undercooling induced by pressurization, and it coincides well with our other results $[43,53,54]$.

\section{Conclusions}

In this work, the synergistic effect of pressurization rate $(0.6-750 \mathrm{MPa} / \mathrm{s})$ and $\beta-\mathrm{NA}$ (WBG-II) on the crystallization behavior of iPP were revealed by means of a homemade pressure device. The results show that the crystal formation of iPP strongly depends on the pressurization rate. The unique polymorphic iPP composed of $\beta, \gamma$, and/or mesomorphic phase can be prepared, and a function of these phase contents and the pressurization rate was established, where three critical pressurization rates marked as $\mathbf{R}_{\mathbf{1}}, \mathbf{R}_{\mathbf{2}}$, and $\mathbf{R}_{\mathbf{3}}$ were distinctly determined. Under the low pressurization rate range below $\mathbf{R}_{\mathbf{1}}, \beta$ - and $\gamma$-iPP grow competitively within different spherulites, while the best pressurization rate for $\beta$-iPP growth is $\mathbf{R}_{\mathbf{1}}$. Once that rate exceeds $\mathbf{R}_{\mathbf{2}}$, multiphase iPP including $\beta, \gamma$, and/or mesomorphic phases can be obtained, while pure mesophase can be obtained after it reaches $\mathbf{R}_{3}$. $\beta$-NA can significantly promote the formation of $\gamma$-iPP in a wide pressurization rate range between 3.8 to $75 \mathrm{MPa} / \mathrm{s}$, and thereby suppress mesophase generation. The difference in $\beta$-NA content effect on crystallization is visible in low pressurization rate ranges lower than $\mathbf{R}_{\mathbf{1}}$, where more nucleating agents promote more $\beta$-iPP. Finally, a theoretical model of the pressurization-induced crystallization was proposed, which offers a novel approach to develop polymorphic crystallization or further optimize mechanical properties of iPP products. 
Author Contributions: In this study, W.J. conceived and designed the experimental model; W.J. and X.L. performed and characterized the experiments and results. M.X. and J.L. analyzed the experimental results. R.Z. and C.S. (Chunguang Shao) wrote and validated the manuscript, and., C.L. and C.S. (Changyu Shen) read the manuscript. All authors have discussed the results and approved the final version of the manuscript.

Funding: This study was supported by the National Natural Science Foundation of China (grant nos. 51573171).

Institutional Review Board Statement: Not applicable.

Informed Consent Statement: Not applicable.

Data Availability Statement: Not applicable.

Conflicts of Interest: The authors declare no conflict of interest.

\section{References}

1. De Rosa, C.; Auriemma, F.; Di Girolamo, R.; De Ballesteros, O.R. Crystallization of themesomorphic form and control of the molecular structure for tailoring the mechanical properties of isotactic polypropylene. J. Polym. Sci. Part B Polym. Phys. 2014, 52, 677-699. [CrossRef]

2. Zia, Q.; Radusch, H.J.; Androsch, R. Deformation behavior of isotactic polypropylene crystallized via a mesophase. Polym. Bull. 2009, 63, 755-771. [CrossRef]

3. Liu, Z.; Liu, X.; Zheng, G.; Dai, K.; Liu, C.; Shen, C.; Yin, R.; Guo, Z. Mechanical enhancement of melt-stretched beta-nucleated isotactic polypropylene: The role of lamellar branching of beta-crystal. Polym. Test. 2017, 58, 227-235. [CrossRef]

4. Liu, Z.; Liu, X.; Li, L.; Zheng, G.; Liu, C.; Qin, Q.; Mi, L. Crystalline structure and remarkably enhanced tensile property of $\beta$-isotactic polypropylene via overflow microinjection molding. Polym. Test. 2019, 76, 448-454. [CrossRef]

5. Binsbergen, F.L.; De Lange, B.G.M. Morphology of polypropylene crystallized from the melt. Polymer 1968, 9, 23-40. [CrossRef]

6. Lotz, B.; Wittmann, J.C.; Lovinger, A.J. Structure and morphology of poly(propylenes): A molecular analysis. Polymer 1996, 37, 4979-4992. [CrossRef]

7. Leugering, H.J.; Kirsch, G.A. Effect of crystallization from oriented melts on crystal structure of isotactic polypropylene. Macromol. Chem. Phys. 1973, 33, 17-23.

8. Meille, S.V.; Bruckner, S.; Porzio, W. $\gamma$-Isotactic polypropylene. A structure with nonparallel chain axes. Macromolecules 1990, 23, 4114-4121. [CrossRef]

9. Mezghani, K.; Phillips, P.J. The $\gamma$-phase of high molecular weight isotactic polypropylene: III. The equilibrium melting point and the phase diagram. Polymer 1998, 39, 3735-3744. [CrossRef]

10. Foresta, T.; Piccarolo, S.; Goldbeck-Wood, G. Competition between $\alpha$ and $\gamma$ phases in isotactic polypropylene: Effects of ethylene content and nucleating agents at different cooling rates. Polymer 2001, 42, 1167-1176. [CrossRef]

11. O'Kane, W.J.; Young, R.J.; Bras, W.; Derbyshire, G.E.; Mant, G.R. Simultaneous SAXS/WAXS and DSC analysis of the melting and re-crystallization behaviour of quenched polypropylene. Polymer 1994, 35, 1352-1358. [CrossRef]

12. Krache, R.; Benavente, R.; López-Majada, J.M.; Pereña, J.M. Competition between $\alpha$, $\beta$, and $\gamma$ Polymorphs in a $\beta$-Nucleated Metallocenic Isotactic Polypropylene. Macromolecules 2007, 40, 6871-6878. [CrossRef]

13. Shi, S.; Liu, Y.; Nie, M.; Wang, Q. Nacre-mimetic polypropylene featuring heterogeneous distribution of polymorphic compositions via controlled diffusion of $\beta$-nucleating agent. Ind. Eng. Chem. Res. 2019, 58, 4116-4124. [CrossRef]

14. Yang, S.; Chen, Y.; Deng, B.; Lei, J.; Li, L.; Li, Z. Window of pressure and flow to produce $\beta$-crystals in isotactic polypropylene mixed with $\beta$-nucleating agent. Macromolecules 2017, 50, 4807-4816. [CrossRef]

15. Luo, F.; Geng, C.; Wang, K.; Deng, H.; Chen, F.; Fu, Q.; Na, B. new understanding in tuning toughness of $\beta$-polypropylene: The role of $\beta$-nucleated crystalline morphology. Macromolecules 2009, 42, 9325-9331. [CrossRef]

16. Mani, M.R.; Chellaswamy, R.; Marathe, Y.N.; Pillaiet, V.K. New understanding on regulating the crystallization and morphology of the $\beta$-polymorph of isotactic polypropylene based on carboxylate-alumoxane nucleating agents. Macromolecules 2016, 49, 2197-2205. [CrossRef]

17. Chen, Y.; Zhong, G.; Lei, J.; Li, Z. In situ synchrotron x-ray scattering study on isotactic polypropylene crystallization under the coexistence of shear flow and carbon nanotubes. Macromolecules 2011, 44, 8080-8092. [CrossRef]

18. Blomenhofer, M.; Ganzleben, S.; Hanft, D.; Schmidt, H.W.; Kristiansen, M.; Smith, P.; Stoll, K.; Mäder, D.; Hoffmann, K. "Designer" nucleating agents for polypropylene. Macromolecules 2005, 38, 3688-3695. [CrossRef]

19. Sowinski, P.; Piorkowska, E.; Boyer, S.A.E.; Haudin, J.M.; Zapala, K. The role of nucleating agents in high-pressure-induced gamma crystallization in isotactic polypropylene. Colloid Polym. Sci. 2015, 293, 665-675. [CrossRef] [PubMed]

20. Zapala, K.; Piorkowska, E.; Hiltner, A.; Baer, E. High-pressure crystallization of isotactic polypropylene droplets. Colloid Polym. Sci. 2012, 290, 1599-1607. [CrossRef] 
21. Li, X.; Jia, W.; Dong, B.; Yuan, H.; Su, F.; Wang, Z.; Wang, Y.; Liu, C.; Shen, C.; Shao, C. Structure and mechanical properties of multi-walled carbon nanotubes-filled isotactic polypropylene composites treated by pressurization at different rates. Polymers 2019, 11, 1294. [CrossRef]

22. Sowinski, P.; Piorkowska, E.; Boyer, S.A.E.; Haudin, J.M. On the structure and nucleation mechanism in nucleated isotactic polypropylene crystallized under high pressure. Polymer 2018, 151, 179-186. [CrossRef]

23. Geil, P.H.; Anderson, F.R.; Wunderlich, B.; Arakawa, T. Morphology of polyethylene crystallized from the melt under pressure. J. Polym. Sci. Part A 1964, 2, 3707-3720. [CrossRef]

24. Rees, D.V.; Bassett, D.C. Origin of extended-chain lamellae in polyethylene. Nature 1968, 219, 368-370. [CrossRef]

25. Van Drongelen, M.; Van Erp, T.B.; Peters, G.W.M. Quantification of non-isothermal, multi-phase crystallization of isotactic polypropylene: The influence of cooling rate and pressure. Polymer 2012, 53, 4758-4769. [CrossRef]

26. Meille, S.V.; Brückner, S. Non-parallel chains in crystalline $\gamma$-isotactic polypropylene. Nature 1989, 340, 455-457. [CrossRef]

27. Angelloz, C.; Fulchiron, R.; Douillard, A.; Chabert, B. Crystallization of isotactic polypropylene under high pressure ( $\gamma$ phase). Macromolecules 2000, 33, 4138-4145. [CrossRef]

28. Huang, J.; Fu, X.; Shao, C.; Ma, Z.; Wang, Y.; Liu, C.; Shen, C. High-pressure induced formation of isotactic polypropylene mesophase: Synergistic effect of pressure and pressurization rate. Polym. Eng. Sci. 2019, 59, 439-446. [CrossRef]

29. Yu, P.; Wang, W.; Wang, R.; Lin, S. Understanding exceptional thermodynamic and kinetic stability of amorphous sulfur obtained by rapid compression. Appl. Phys. Lett. 2009, 94, 011910. [CrossRef]

30. Yuan, C.; Hong, S.; Li, X.; Shen, R.; He, Z.; Lv, S.; Liu, X.; Lv, J.; Xi, D. Rapid compression preparation and characterization of oversized bulk amorphous polyeth-er-ether-ketone. J. Phys. D Appl. Phys. 2011, 44, 165405. [CrossRef]

31. Obadal, M.; Čermák, R.; Stoklasa, K. Tailoring of three-phase crystalline systems in isotactic poly(propylene). Macromol. Rapid Commun. 2005, 26, 1253-1257. [CrossRef]

32. Yang, G.; Li, X.; Chen, J.; Yang, J.; Huang, T.; Liu, X.; Wang, Y. Crystallization behavior ofisotactic polypropylene induced by competition action of $\beta$ nucleating agent and high pressure. Colloid Polym. Sci. 2012, 290, 531-540. [CrossRef]

33. Sowinski, P.; Piorkowska, E.; Boyer, S.A.E.; Haudin, J.M. Nucleation of crystallization of isotactic polypropylene in the gamma form under high pressure in noni-sothermal conditions-ScienceDirect. Eur. Polym. J. 2016, 85, 564-574. [CrossRef]

34. Fu, X.; Jia, W.; Li, X.; Wang, Y.; Wang, Z.; Liu, C.; Shen, C.; Shao, C. Phase transitions of the rapid compression-induced mesomorphic isotactic polypropylene under high-pressure annealing. J. Polym. Sci. Part B Polym. Phys. 2019, 57, 651-661. [CrossRef]

35. Luo, F.; Wang, K.; Ning, N.; Geng, C.; Deng, H.; Chen, F.; Fu, Q.; Qian, Y. Dependence of mechanical properties on $\beta$-form content and crystalline morphology for $\beta$-nucleated isotactic polypropylene. Polym. Adv. Technol. 2010, 22, 2044-2054. [CrossRef]

36. Zhao, J.; Wang, Z.; Niu, Y.; Hsiao, B.S.; Piccarolo, S. Phase transitions in prequenched mesomorphic isotactic polypropylene during heating and annealing processes as revealed by simultaneous synchrotron SAXS and WAXD technique. J. Phys. Chem. $B$ 2012, 116, 147-153. [CrossRef]

37. Shi, Q.; Cai, C.; Ke, Z.; Yin, L.; Liu, Y.; Zhu, L.; Yin, J. Effect of the nucleating agent 1,3:2,4-di(3,4-dimethylbenzylidene) sorbitol on the $\gamma$ phase content of propylene/ethylene copolymer. Eur. Polym. J. 2008, 44, 2385-2391. [CrossRef]

38. Stretz, H.A.; Paul, D.R. Properties and morphology of nanocomposites based on styrenic polymers. Part I: Styrene-acrylonitrile co-polymers. Polymer 2006, 47, 8123-8136. [CrossRef]

39. Androsch, R.; Lorenzo, M.; Schick, C. Mesophases in polyethylene, polypropylene, and poly(1-butene). Polymer 2010, 51, 4639-4662. [CrossRef]

40. Odell, J.A.; Grubb, D.T.; Keller, A. A new route to high modulus polyethylene by lamellar structures nucleated onto fibrous substrates with general implications for crystallization behaviour. Polymer 1978, 19, 617-626. [CrossRef]

41. Troisi, E.M.; Portale, G.; Ma, Z. Unusual Melting Behavior in Flow Induced Crystallization of LLDPE: Effect of Pressure. Macromolecules 2015, 48, 2551-2560. [CrossRef]

42. Hong, S.M.; Chen, L.Y.; Liu, X.R.; Wu, X.H.; Su, L. High pressure jump apparatus for measuring Grúneisen parameter of NaCl and studying metastable amorphous phase of poly (ethylene terephthalate). Rev. Sci. Instrum. 2005, 76, 053905-053910. [CrossRef]

43. Jia, R.; Shao, C.G.; Su, L.; Huang, D.H.; Liu, X.R.; Hong, S.M. Rapid compression induced solidification of bulk amorphous sulfur. J. Phys. D Appl. Phys. 2007, 40, 3763-3766. [CrossRef]

44. Cai, Z.; Zhang, Y.; Li, J.; Shang, Y.; Huo, H.; Feng, J.; Funari, S.S.; Jiang, S. Temperature-dependent selective crystallization behavior of isotactic polypropylene with a $\beta$-nucleating agent. J. Appl. Polym. Sci. 2013, 128, 628-635. [CrossRef]

45. Mezghani, K.; Phillips, P.J. The $\gamma$-phase of high molecular weight isotactic polypropylene. II: The morphology of the $\gamma$-form crystallized at $200 \mathrm{MPa}$. Polymer 1997, 38, 5725-5733. [CrossRef]

46. Lotz, B. $\alpha$ and $\beta$ phases of isotactic polypropylene: A case of growth kinetics 'phase reentrency' in polymer crystallization. Polymer 1998, 39, 4561-4567. [CrossRef]

47. Zhang, B.; Wang, B.; Chen, J. Flow-induced dendritic $\beta$-form isotactic polypropylene crystals in thin films. Macromolecules 2016, 49, 5145-5151. [CrossRef]

48. Erp, T.; Balzano, L.; Spoelstra, A.B. Quantification of non-isothermal, multi-phase crystallization of isotactic polypropylene: The influence of shear and pressure. Polymer 2012, 53, 5896-5908. [CrossRef]

49. Burns, J.R.; Turnbull, D. Kinetics of crystal nucleation in molten isotactic polypropylene. J. Appl. Phys. 1966, 37, 4021-4026. [CrossRef] 
50. Jin, Y.; Hiltner, A.; Baer, E.; Masirek, R. Formation and transformation of smectic polypropylene nanodroplets. J. Polym. Sci. Part B Polym. Phys. 2010, 44, 1795-1803. [CrossRef]

51. Ostwald, W. Studien über die Bildung und Umwandlung fester Körper. Z. Phys. Chem. 1897, 22, 289-330. [CrossRef]

52. Threlfall, T. Structural and Thermodynamic Explanations of Ostwald's Rule. Org. Process. Res. Dev. 2003, 7, 1017-1027. [CrossRef]

53. Liu, X.; Zhang, L.; Yuan, C.; Jia, R.; Shao, C.; Wang, M.; Hong, S. A study of the pressure-induced solidification of polymers. Polymers 2018, 10, 847. [CrossRef] [PubMed]

54. Hong, S.; Liu, X.; Su, L.; Su, L.; Huang, D.; Li, L. Rapid compression induced solidification of two amorphous phases of poly(ethylene terephthalate). J. Phys. D Appl. Phys. 2006, 39, 3684-3688. [CrossRef] 